\title{
Carlos Contreras Gómez
}

\section{IMPOSICIÓN SOBRE LAS TRANSACCIONES FINANCIERAS EN UN MUNDO GLOBALIZADO}

En el seno de la Unión Europea se está llevando a cabo el experimento fiscal internacional más relevante en la historia por lo que respecta a la implantación de impuestos sobre transacciones financieras. El impuesto que se propone establecer grava la mayoría de instrumentos financieros en diez Estados miembros. En vista de que el proceso de implantación de este impuesto europeo general y coordinado no termina de ver la luz, países como Francia e Italia han establecido impuestos sobre las transacciones bursátiles de manera unilateral. España se está también sumando a este club. En este articulo se revisan los argumentos de defensa y de crítica sobre el establecimiento de esta figura tributaria, y se adelantan los efectos que puede tener sobre la liquidez del mercado en el caso español.

\section{Taxing financial transactions in a globalized world}

As far as taxes on securities transactions are concerned, the most important international tax experiment in history is currently taking place within the European Union. The proposed tax covers most financial instruments in ten Member States. In light of the fact that the process of implementing this general and coordinated European tax has not yet been completed, countries such as France and Italy have unilaterally established stock exchange taxes. Spain is also joining this club. This article reviews some for and against arguments on the establishment of this tax figure, and anticipates the effects it may have on market liquidity in the Spanish case.

Palabras clave: impuesto sobre transacciones financieras, tasa Tobin, liquidez, volatilidad, equidad. Keywords: securities transaction tax, financial transaction tax, Tobin tax, liquidity, volatility, equity. JEL: H21, H22, H23, H25, G21.

1. Introducción

Recientemente se ha reactivado el debate sobre la conveniencia o no de establecer impuestos sobre las transacciones financieras (ITF). Con el denominado por algunos Robin Hood tax ocurre lo mismo que con las

\footnotetext{
* Profesor Titular de la UCM (Departamento de Economía Aplicada: Economía Pública y Política Económica) en excedencia. Versión de noviembre de 2020.

https://doi.org/10.32796/ice.2020.917.7128
}

aventuras del mítico héroe del bosque de Sherwood: ha despertado gran interés en la clase política y en el pueblo (Sachs, 2010; Coelho, 2016). El coro de defensores de este impuesto es heterogéneo, incluyendo activistas y políticos que tienen la esperanza de aumentar la recaudación sin asumir un coste político, aprovechando la ira popular hacia la banca a raíz de la crisis financiera iniciada en 2007. Por el contrario, en la industria financiera los detractores del impuesto sobre las transacciones financieras son legión. Los economistas mantienen una importante controversia 
al respecto de esta figura impositiva, y recientemente se ha acumulado una extensa literatura académica sobre las ventajas y los inconvenientes esperados de su establecimiento.

Los defensores del impuesto creen que su introducción permitiría la obtención de una elevada recaudación y reduciría tanto la negociación especulativa como la volatilidad de los precios de los activos financieros. Además, esperan que un nivel importante de recursos tecnológicos y de capital humano se desviarían de la actividad de trading especulativo, que no ofrece valor social, a la producción real; y creen que su introducción contribuiría a mejorar el nivel de equidad en la sociedad.

Por el contrario, aquellos que se oponen a este impuesto consideran que, al recaer sobre producción intermedia, genera una cascada de efectos desiguales por activos y sectores, produciendo ineficiencia económica. Además, esperan un impacto negativo sobre la inversión (al elevar el coste del capital), y un incremento en la volatilidad del precio de los activos del mercado financiero (al reducir la liquidez). Por otra parte, consideran que la reducción de la actividad especulativa implica un ajuste más lento de los precios ante la incorporación de nueva información. También dudan de la capacidad recaudatoria del impuesto, ante el importante efecto contractivo sobre la actividad de negociación y ante la posibilidad de comportamientos de elusión fiscal. Y tampoco creen que el impuesto genere mayor progresividad en el sistema impositivo, ya que la carga del impuesto se traslada a los ahorradores, afectando particularmente a los partícipes de los fondos de inversión y de pensiones y a clientes finales de los bancos.

Este artículo tiene como objetivo ofrecer una panorámica de la evolución de esta figura tributaria, revisar los argumentos de defensa y de crítica sobre su establecimiento, aportar una visión general de los resultados empíricos sobre el tema, y estimar los efectos que puede tener sobre la liquidez del mercado bursátil español. El resto del artículo se organiza del siguiente modo. En el segundo apartado se ofrece una panorámica de la evolución de los impuestos sobre las transacciones financieras. En los apartados tercero y cuarto se revisan respectivamente los argumentos que la literatura económica ofrece en favor y en contra de su introducción. El apartado quinto ofrece la evidencia empírica internacional sobre los efectos de este impuesto. El apartado sexto ofrece una estimación del efecto esperado sobre la liquidez bursátil en el caso español. Finalmente, el apartado séptimo ofrece algunas conclusiones.

\section{Evolución de los impuestos sobre transacciones financieras}

Cuando se trata de gravar la industria financiera hay esencialmente tres enfoques posibles: i) gravar los servicios de intermediación; ii) utilizar impuestos especiales sobre las entidades bancarias, mediante tasas sobre el saldo de determinadas partidas del balance ${ }^{1}$, mediante aumentos en el tipo del impuesto de sociedades o limitando la deducibilidad de determinados gastos $^{2}$; y iii) gravar directamente las transacciones financieras. Este último enfoque es el que es objeto de análisis en este artículo.

Hay básicamente tres modalidades de gravamen sobre transacciones financieras: los impuestos sobre las transacciones cambiarias, currency transaction taxes, que gravan específicamente las transacciones de cambio de divisa y potencialmente también sus

\footnotetext{
En España algunas comunidades autónomas establecieron impuestos sobre depósitos en entidades de crédito y el Gobierno central reaccionó introduciendo por medio de la Ley 16/2012 un impuesto de este tipo aplicable a las entidades de crédito y a las sucursales de entidades extranjeras en territorio español, con un tipo de gravamen del $0 \%$, con la voluntad de preservar para sí esta competencia. Sin embargo, en julio de 2014 se elevó el tipo impositivo de este IDEC al 0,03\% con objeto de compensar a las comunidades que habían introducido esta figura impositiva previamente.

2 En países como Reino Unido y Estados Unidos respectivamente se han impuesto gravámenes especiales sobre los bonus pagados a directivos del sector bancario o limitaciones a la deducibilidad fiscal de los gastos de personal en el caso de salarios por encima de determinados techos en este sector.
} 
derivados (futuros, opciones y swaps); los impuestos sobre las transacciones de valores, securities transactions taxes, que gravan operaciones en todos o ciertos tipos de valores (acciones, deuda, pagarés y sus derivados); $y$, finalmente, los impuestos sobre el registro de emisión de valores, que recaen sobre las operaciones del mercado primario de acciones, de bonos y, en ocasiones, sobre la concesión de créditos hipotecarios.

La recomendación de establecer impuestos sobre las operaciones de valores y cambiarias se remonta a la propuesta de mediados de los años 30, elaborada por John Maynard Keynes (1936). Posteriormente, James Tobin $(1974 ; 1978)$ retomó el tema proponiendo «arrojar algo de arena en las ruedas» de los excesivamente eficientes mercados de divisas internacionales, lo que vino a denominarse tasa Tobin. Su propuesta recibió una notable atención académica, aunque apenas tuvo repercusión en la práctica fiscal. Durante las décadas siguientes esta tasa no se implantó en ningún país, a pesar de que ese período coincidió con un proceso notable de innovación financiera y de proliferación de instrumentos financieros derivados, que contribuyó a un incremento espectacular en la cifra de contratación en los mercados financieros.

Desde finales de los años ochenta se produjo, además, una creciente inestabilidad en los mercados $y$ diversas crisis financieras, de diferente magnitud y naturaleza, incluyendo el minicrack bursátil de octubre de 1987 en Estados Unidos; la crisis del Mecanismo Europeo de Tipos de Cambios en septiembre de 1992; la crisis financiera asiática de julio de 1997; el estallido de la burbuja bursátil de Internet en marzo del año 2000. Más recientemente hemos asistido al episodio conocido como Flash Crash o Crash 2:45 en la Bolsa de Nueva York en mayo de 2010; la crisis subprime que se tradujo en una crisis financiera internacional, y, en el caso europeo, en una auténtica crisis de deuda soberana durante 2011-2012. Y el episodio de crisis bursátil de marzo de 2020 causada por la pandemia del coronavirus. Estos acontecimientos han contribuido a reactivar el debate sobre las ventajas y los inconvenientes de introducir un impuesto sobre las transacciones financieras.

En 1984 se estableció en Suecia un impuesto que recaía sobre la compraventa de acciones de compañías suecas. Eran transacciones sujetas aquellas en las que participaban tanto clientes nacionales como extranjeros. Si ambas partes de la operación eran no residentes, el impuesto se aplicaba únicamente cuando los activos estaban registrados en sistemas de compensación y liquidación suecos. Se trataba de un impuesto ad valorem en el que la base imponible del impuesto era el valor de la negociación realizada. Eran sujetos pasivos del impuesto las entidades de servicios de intermediación financiera. El tipo impositivo inicial era del $1 \%$ (y en 1986 se elevó al $2 \%$ ). Además, en 1989 se estableció un segundo impuesto sobre la compraventa de deuda pública y de deuda corporativa de emisores con residencia sueca, con tipos impositivos entre el $0,02 \%$ y el $0,03 \%$ dependiendo del vencimiento. En ambos impuestos la actividad en el mercado primario estaba exenta. En vista del fuerte impacto de deslocalización de la actividad financiera hacia la plaza de Londres, el impuesto que recaía sobre la contratación de acciones se suprimió en 1990. Además, se produjo una acusada disminución en la negociación de títulos de deuda pública sueca y se observó un desplazamiento por parte de los inversores hacia activos no gravados. El impuesto que recaía sobre la negociación de renta fija se eliminó también en 1991 (Umlauf, 1993).

En la actualidad, algunos países del G-20 tienen establecido algún tipo de impuesto sobre transacciones en los mercados financieros. En la mayoría de los casos se trata de impuestos ad valorem sobre la negociación de las acciones. La recaudación obtenida mediante estos impuestos es, en general, reducida y el número de países que gravan las transacciones financieras ha estado en declive durante años. Esta tendencia se justifica por: i) el temor de los Gobiernos a perder competitividad a favor de otros centros financieros, en un contexto de 
mayor movilidad del capital internacional y de iniciativas gubernamentales para fomentar el desarrollo de las bolsas de valores locales; ii) el intento de los poderes ejecutivos de evitar un incremento en los costes de capital de las empresas, para no entorpecer la inversión; y iii) la consideración de que las distorsiones generadas por este tipo de impuestos no se ven convenientemente compensadas por los ingresos fiscales (Pollin et al., 2003). En las tres últimas décadas, un buen número de países han eliminado este tipo de impuestos parciales o bien han reducido su alcance mediante exenciones. Entre otros, Estados Unidos, Países Bajos, Alemania, Suecia, Dinamarca, Japón, Austria, Irlanda y Bélgica, son ejemplos de esta evolución. En concreto, dentro de la Unión Europea (UE), tanto la normativa como la jurisprudencia del Tribunal de Justicia de la UE habían contribuido hasta hace poco a desincentivar los impuestos sobre las transacciones financieras. Así, la Directiva 69/335/CEE prohibió establecer impuestos diferentes a los de capital duty ${ }^{3}$. Desde el último cambio de la Directiva en 1985, los Estados miembros de la UE están autorizados a imponer un impuesto sobre las aportaciones de capital a un tipo máximo del $1 \%$. Además, con el fin de fortalecer el mercado interior y promover la integración de los mercados de capitales europeos, la Directiva prohibió gravar con impuestos la emisión de acciones y otros valores. En diciembre de 2006, la Comisión Europea puso en marcha una propuesta para eliminar gradualmente el capital duty en los Estados miembros, limitando el tipo impositivo en una primera etapa, en 2008 , a un $0,5 \%$ para luego abolirlo por completo en 2010. En la misma línea, es de relevancia la Sentencia del Tribunal de Justicia de la UE de 2004 estableciendo la violación de la Directiva 69/335/CEE por parte del impuesto belga sobre las operaciones bursátiles por contravenir lo dispuesto en la Directiva 69/335/CEE del Consejo.

3 Impuestos que gravan la constitución de sociedades, el aumento de capital y el traslado de sociedades. En nuestro sistema tributario equivale al gravamen de operaciones societarias y, en ciertos casos, al de actos jurídicos documentados.
De momento, la práctica fiscal ha consistido en impuestos selectivos que recaen sobre la negociación de algún tipo de instrumento. Además, se han aplicado siempre de forma no coordinada internacionalmente y sus ingresos se utilizan únicamente para financiar presupuestos nacionales. Frente a esta situación, se ha defendido la oportunidad de establecer un impuesto general y uniforme sobre transacciones financieras con aplicación coordinada internacionalmente por tres motivos: i) por su superioridad desde la perspectiva de la neutralidad fiscal, al no discriminar unos instrumentos frente a otros; ii) porque al aumentar la base imponible del impuesto, para un nivel esperado de recaudación fiscal, el tipo de gravamen requerido será menor, generándose una menor distorsión; y iii) si se implanta de forma coordinada y simultánea en los principales países, se reducirían los potenciales problemas de elusión fiscal.

Como resultado de la crisis iniciada en 2007, instituciones internacionales como el Fondo Monetario Internacional (FMI) y el Banco Internacional de Pagos (BIS) han trabajado en la idea de establecer «una nueva arquitectura financiera». En este debate, ha emergido la cuestión de la imposición sobre las transacciones financieras. Los líderes del G-20 en su reunión en Pittsburg en septiembre de 2009 encargaron al FMl explorar cómo el sector financiero podría realizar una contribución justa y sustancial al pago de las cargas asociadas a las intervenciones del Gobierno para rescatar el sistema bancario. En su respuesta, el FMI (2010) propuso un enfoque dual: recomendó la adopción de gravámenes sobre las instituciones financieras, bank levy, para pagar los costes asociados a la resolución de posibles crisis financieras futuras, por un lado, y la implantación de un impuesto sobre las actividades financieras (IAF) que gravase la suma de las rentas de bancos, sociedades gestoras de instituciones de inversión colectiva y de pensiones, y de compañías de intermediación de valores, por otro; sin descartar tampoco el uso de impuestos sobre las transacciones financieras para otros fines. 
En este contexto, en el seno de la Unión Europea se está llevando a cabo el experimento fiscal internacional más relevante en la historia por lo que respecta a la implantación de impuestos sobre transacciones financieras. Se trata de un impuesto general que incluye la mayoría de instrumentos financieros y afecta a un numeroso conjunto de países. Desde 2009 los partidarios del impuesto pasaron a la ofensiva, apoyados por los «efectos de choque» de la crisis financiera. En 2010 la Comisión Europea propuso la adopción de un impuesto general sobre transacciones financieras en todos los Estados miembros, si bien finalmente 16 Estados se opusieron a su implantación. En una segunda fase se buscaron los mecanismos legales para su implementación y se definieron los elementos impositivos. En enero de 2013 el Consejo de la Unión Europea autorizó el procedimiento de cooperación reforzada para que, ante la falta de unanimidad en el seno de la Unión Europea (UE), 11 Estados miembros -Alemania, Austria, Bélgica, Eslovaquia, Eslovenia, España, Estonia, Francia, Grecia, Italia y Portugal-, denominados a estos efectos Estados Miembros Participantes (EMP), pudieran avanzar en la implantación de este tributo de forma armonizada. En marzo del mismo año, el Consejo de la UE publicó una Propuesta de Directiva sobre la materia. La siguiente fase en este proceso ha estado marcada por una fuerte y bien organizada contraofensiva por parte de la industria financiera, así como por la acumulación de literatura académica contra el impuesto. En el terreno político hemos visto conflictos en el grupo de EMP (entre Alemania y Francia) y Eslovenia abandonó el grupo de Estados que desean incorporar esta figura tributaria. Esta fase parecía terminar con una derrota de los partidarios del ITF. A fecha de hoy el impuesto europeo general sobre transacciones financieras no se ha establecido y los expertos en fiscalidad en el ámbito de la Unión Europea parecen estar actualmente más concentrados en el impacto de la economía digital en la recaudación fiscal de los países europeos, y en el diseño de políticas que cierren los portillos legales a la elusión fiscal, particularmente por parte de multinacionales.

El diseño del hecho imponible de un impuesto sobre transacciones financieras implica definir el tipo de instrumento, el tipo de operación y el tipo de mercado afectado. Por lo que respecta al impuesto europeo propuesto, las transacciones gravadas y no gravadas son las que se indican en las Tablas 1 y 2 .

De acuerdo con el impuesto europeo, una transacción está sujeta si una de las partes está establecida en el territorio de un Estado miembro participante. Se entiende que la imposición tiene lugar en el EMP en cuyo territorio esté establecida la entidad si esta es parte de la transacción y actúa por cuenta propia o por cuenta de terceros, o bien en nombre de una de las partes de la transacción (principio de residencia). Si ninguna parte en la transacción está establecida en un EMP pero negocian instrumentos emitidos en un EMP, las transacciones también quedarían sujetas (principio de emisión).

Los sujetos pasivos del impuesto son casi todo tipo de intermediarios, incluyendo empresas de servicios de inversión, mercados organizados, entidades de crédito, empresas de seguros y reaseguros, instituciones de inversión colectiva y sus gestoras, fondos de pensiones y sus gestoras, fondos de inversión alternativos y sus gestoras, sociedades de cartera, empresas de arrendamiento financiero, entidades especializadas en titulizaciones, y entidades de cometido financiero especial ${ }^{4}$. Existe una cláusula de escape para aquellas entidades que, a pesar de estar sujetas por el criterio de ser un establecimiento en un Estado miembro participante, puedan demostrar la desconexión entre la transacción y la realidad económica subyacente (o la no existencia real de una transacción financiera).

Por lo que respecta a los tipos impositivos, la Tabla 3 muestra las tarifas mínimas que deberían establecer los Estados miembro participantes.

\footnotetext{
4 Si estas representan más del $50 \%$ de la cifra anual media de ingresos.
} 
TABLA 1

TRANSACCIONES FINANCIERAS GRAVADAS

Tipo de transacción

Compra o venta por importe bruto de un instrumento financiero, antes de compensación o liquidación. Instrumentos financieros: valores negociables e instrumentos del mercado monetario. Transacción significa tanto cesión de propiedad como cesión de riesgo.
La cesión entre entidades de un mismo grupo de un instrumento financiero cuando se transfiera el riesgo asociado está gravada aunque no se trate de una compraventa.

Participaciones y acciones de organismos de inversión colectiva en valores mobiliarios (OICVM) y fondos de inversión alternativa (FIA).

Productos estructurados: ciertos pagarés, certificados de opción de compra y titulizaciones de hipotecas, préstamos y de seguros.

Pactos de recompra y de recompra inversa (REPOs).

Acuerdos de préstamo de valores.

En principio, solo darían lugar a una transacción.

Contratos de opciones, futuros, permutas (swaps), acuerdos de tipos de interés a plazo, derivados relacionados con valores, divisas, tipos de interés o rendimientos, índices financieros o medidas financieras o relacionadas con variables climáticas, gastos de transporte, autorizaciones de emisión o tipos de inflación u otras estadísticas económicas oficiales que puedan liquidarse en de crédito. Contratos financieros por diferencias.

Tipos de mercados

Transacciones sometidas al impuesto si se realizan en mercados regulados, sistemas multilaterales de negociación o internalizadores sistemáticos y en mercados no organizados (over the counter).

FUENTE: Contreras y Contreras (2018).

En vista de que el proceso de implantación del impuesto general y coordinado sobre transacciones financieras no veía la luz, algunos países de la Unión han establecido impuestos parciales sobre transacciones financieras de manera unilateral. Por una parte, en 2012 el Gobierno francés promovió un impuesto sobre la negociación de acciones, que entró en vigor en agosto, y que grava con una tasa del $0,2 \%{ }^{5}$ la compraventa de acciones de aquellas compañías con sede en territorio francés y con una capitalización bursátil de al menos mil millones de

\footnotetext{
5 La tasa que se había propuesto en febrero se situaba en un $0,1 \%$ pero en julio se duplicó y se introdujo, además, un tipo impositivo del $1,0 \%$ para transacciones en mercados OTC.
}

euros $^{6}$. Inicialmente había una lista de 109 compañías con acciones cuya contratación estaba sujeta, produciéndose una revisión anual de esta lista. La obligación tributaria nace en este impuesto de la contratación de las acciones de estas compañías en cualquier mercado, con independencia de donde estuvieran cotizando. Las transacciones del mercado primario están exentas. Otras exenciones del impuesto incluyen los contratos financieros de opciones, futuros y warrants, la negociación de acciones para la cobertura de planes de opciones para empleados (ESOPs), así como la actividad

\footnotetext{
6 También incluye un impuesto sobre trading de alta frecuencia (HFT) —cancelación o modificación de órdenes representando más del $80 \%$ de las órdenes ejecutadas, con un tipo impositivo del 0,01\%-.
} 
TABLA 2

\section{OPERACIONES NO GRAVADAS POR EL IMPUESTO DE TRANSACCIONES FINANCIERAS}

\begin{tabular}{lc}
\hline Tipo de transacción Comentarios & Comion \\
\hline
\end{tabular}

Realizadas en mercados primarios.

Realizadas con Bancos Centrales de los Estados miembros participantes y con el Banco Central Europeo.

De reestructuración al amparo de la Directiva 2008/7/CEc.

Operaciones al contado de divisas y de materias primas.

Contratos de seguros, préstamos hipotecarios, créditos al consumo y servicios de pago.
Se incluyen como operaciones de primario las emisiones de participaciones en OICVM $^{a}$ y FIA ${ }^{b}$.

Ciertos pagarés, certificados de opción de compra y titulizaciones de hipotecas, préstamos y de seguros.

Los contratos de derivados sobre divisas y materias primas sí están gravados.

No se gravan las actividades financieras cotidianas de empresas y familias. La posterior negociación a través de productos estructurados sí está gravada.

NOTAS: (a) Organismos de inversión colectiva en valores mobiliarios. (b) Fondos de inversión alternativos. (c) Se consideran operaciones de reestructuración: la transmisión, por una o varias sociedades de capital, de la totalidad de su patrimonio, o de una o más ramas de su actividad, a una o más sociedades de capital en vías de constitución o ya existentes; o bien la adquisición, por una sociedad de capital en vías de constitución o ya existente, de participaciones que representen la mayoría de los derechos de voto de otra sociedad de capital, siempre que la contrapartida de las participaciones adquiridas consista, al menos parcialmente, en valores representativos del capital de la primera de dichas sociedades.

FUENTE: Contreras y Contreras (2018).

desarrollada por los creadores de mercado. La recaudación obtenida de este impuesto apenas ha alcanzado el $40 \%$ inicialmente estimado por el Gobierno. El déficit de ingresos impositivos se debe particularmente al descenso en la negociación de alta frecuencia y a un efecto deslocalización entre plataformas (Coelho, 2016).

Por su parte, en Italia, en diciembre de 2012 se aprobó un impuesto que entró en vigor en marzo de 2013, sobre las transacciones de acciones emitidas por sociedades residentes italianas con una capitalización igual o mayor a 500 millones de euros. Está sujeta al impuesto la negociación de acciones en mercados organizados y en mercados OTC, incluidas las American Depositary Receipts (ADRs), los derivados y los contratos por diferencias (CFDs). Se trata de un impuesto ad valorem, cuya base imponible es el importe efectivo negociado. El tipo impositivo aplicado desde 2014 es del 0,1\% para transacciones ejecutadas en un mercado organizado y de un $0,2 \%$, cuando se negocian over-the-counter (inicialmente los tipos impositivos aplicados eran respectivamente del $0,12 \%$ y del $0,22 \%$ ). La recaudación obtenida por el impuesto también ha sido hasta la fecha muy inferior a la inicialmente estimada.

En España, el 19 de octubre de 2018 el Consejo de Ministros anunció un Anteproyecto de Ley para la introducción de un impuesto parcial sobre transacciones financieras. La fase de trámite de audiencia e información pública estuvo abierta entre el 23 de octubre y el 15 de noviembre de ese año y se aprobó por parte del Consejo de Ministros el 18 de enero de 2019. El 28 de febrero de 2020 el Boletín de las Cortes publicaba el 
TABLA 3

TARIFAS MÍNIMAS DEL IMPUESTO SOBRE TRANSACCIONES FINANCIERAS

\begin{tabular}{lll}
\hline Tipo de transacción & Base imponible impositivo mínimo
\end{tabular}

Compraventa de instrumentos financieros no derivados.

Compraventa, cesión, intercambio y celebración de contratos derivados (y modificaciones significativas de los mismos).
Cifra de contraprestación con un mínimo equivalente al valor de mercado en condiciones de plena competencia.

Valor nocional o importe nominal subyacente utilizado para calcular los pagos (evitando comportamientos de evasión consistentes en dividir el importe nocional por un factor y multiplicar por el mismo los flujos)

NOTA: Cuando el valor utilizado para determinar la base imponible se exprese total o parcialmente en una moneda distinta a la del Estado miembro participante, el tipo de cambio será el último vendedor registrado en el momento de devengo del impuesto en el mercado de divisas más representativo del EMP.

FUENTE: Contreras y Contreras (2018).

Proyecto de Ley y el impuesto pasaba a la fase de tramitación parlamentaria. El 30 de julio, una vez aprobado por el Congreso, se remitió al Senado, que aprobó el proyecto el 7 de septiembre. Finalmente, el BOE de 16 de octubre de 2020 publicó la Ley 5/2020 de 15 de octubre, del Impuesto sobre las Transacciones Financieras. Está previsto que este impuesto entre en vigor el 16 de enero de 2021. El hecho imponible de este impuesto será la adquisición de acciones emitidas por compañías de nacionalidad española en mercados regulados (según Directiva 2014/65/UE) con una capitalización igual o superior a 1.000 millones de euros. La lista se actualizará anualmente. Se incluye la negociación de ADRs emitidos en cualquier plaza y de certificados de depósito, así como la adquisición de acciones derivadas de la ejecución o liquidación de bonos canjeables y convertibles, de instrumentos derivados y de otros contratos financieros. La nacionalidad de los intervinientes en la transacción no afecta a la sujeción del impuesto. En virtud del denominado principio de emisión, el ITF gravaría cualquier adquisición de acciones emitidas por sociedades cotizadas españolas que cumplan los requisitos, con independencia del lugar donde se realice la adquisición y cualquiera que sea la residencia o el lugar de establecimiento de las personas o entidades que intervengan en la operación. Además, las adquisiciones estarían sujetas, se ejecuten en un centro de negociación o en cualquier otro mercado o sistema de contratación, por un internalizador sistemático, o mediante acuerdos directos entre los contratantes. Las exenciones en el hecho imponible incluyen la contratación de acciones en el mercado primario (OPV y OPS), la actividad de estabilización de precio en OPV y OPS, la negociación intragrupo de acciones vinculadas a la reestructuración de carteras, así como las operaciones vinculadas a la financiación de valores. Otras exenciones se refieren a la actividad de creación de mercado. Se trata de un impuesto ad valorem, cuya base imponible se determina como el importe efectivo negociado. En las operaciones intradía, la base imponible es el neto de compras menos ventas. Son sujetos pasivos del impuesto los intermediarios financieros y los miembros del mercado, tanto cuando actúan por cuenta propia 
como por cuenta de terceros. El tipo impositivo es el $0,20 \%$, y el Gobierno estima una recaudación anual para este tipo impositivo de 850 millones de euros. La estimación de Contreras y Contreras (2015a) sobre la recaudación derivada de la parte de renta variable del ITF europeo aplicado en España se situaba en aquel momento entre los 523 y los 611 millones de euros. Estimaciones más recientes como la de la Autoridad Independiente de Responsabilidad Fiscal (2018) ofrecían un rango de recaudación entre 420 y 850 millones de euros.

\section{3. ¿Por qué gravar las transacciones financieras?}

Los argumentos para gravar las transacciones financieras son variados. Desde que resucitó el interés sobre este gravamen, se han suscitado numerosos debates entre académicos, profesionales de la industria financiera, autoridades y supervisores financieros en relación con sus costes y beneficios (Haq et al., 1996; Jetin \& Denys, 2005). En la actualidad no existe consenso académico respecto de la conveniencia de introducir este tipo de impuesto, al tiempo que la industria financiera muestra una fuerte oposición al mismo. El debate tiene lugar en un momento en el que está en revisión global la imposición de los servicios de intermediación financiera y existen propuestas tanto orientadas a adaptar el IVA a estos servicios, como a la introducción de impuestos especiales de diversa naturaleza sobre las entidades financieras. Además, este debate se produce en un contexto en el que también es objeto de discusión el paradigma de la eficiencia del mercado. La validez del modelo de equilibrio de precios de los activos bajo expectativas racionales compite hoy con el nuevo enfoque de finanzas del comportamiento, que investiga las desviaciones respecto del supuesto de pura racionalidad económica e incluye el análisis del proceso de maximización de la utilidad en presencia de incertidumbre. Esta cuestión es relevante desde la perspectiva del uso de impuestos correctores de comportamientos no deseables en el ámbito de los mercados financieros. Alternativamente a la introducción de un impuesto sobre transacciones financieras, se ha planteado el establecimiento de un impuesto que grave los pánicos y las manías. Este impuesto al pánico (McCulloch, 2010) se orientaría a reducir la volatilidad de los precios de los activos financieros amortiguando el momentum del mercado y mitigando los episodios de burbujas y colapsos ${ }^{7}$. De acuerdo con esta figura tributaria, que concedería a las autoridades más tiempo para afrontar un ajuste ordenado en los mercados, las transacciones financieras serían gravadas con tipos impositivos variables cuya magnitud sería proporcional a la tasa de variación de los precios de los activos financieros o de los tipos de cambio. En escenarios de estabilidad financiera el efecto del impuesto sería marginal, pero durante episodios de fuertes oscilaciones de precios en los mercados, los operadores se enfrentarían a tasas impositivas más penalizadoras. Ello debería desmotivar las operaciones especulativas, amortiguando las desviaciones «no fundamentales» en la evolución de los precios. Cabría esperar que la simple existencia del impuesto amortiguase el ciclo.

\section{Por motivos recaudatorios}

De acuerdo con la teoría de la Hacienda Pública, los impuestos encuentran su justificación en dos razones básicas no mutuamente excluyentes: motivos de suficiencia presupuestaria y objetivos de eficiencia económica. Aunque el argumento recaudatorio puro en el caso de un impuesto sobre las transacciones financieras es defendido por algunos autores (Kiefer, 1990), otros autores consideran que esta no es una justificación particularmente fuerte en el caso de este tipo de tributo, ya que en gran parte las transacciones financieras ejecutadas deben considerarse "producción intermedia»

\footnotetext{
7 Un tributo que está en línea con la propuesta de Spahn (1995) de introducción de una tasa Tobin de dos niveles, con un tipo impositivo reducido para períodos ordinarios y una sobretasa para períodos de inestabilidad.
} 
(Darvas \& Von Weizsäcker, 2010). Si los mercados contribuyen a una asignación eficiente del riesgo, el gravamen de esta actividad producirá distorsiones ineficientes. Frente a esta consideración tres argumentos apoyan la lógica de gravar las transacciones financieras en tanto que fuente potencial de recaudación fiscal: i) el sector financiero esté infragravado en comparación con otros sectores y un ITF podría contribuir a remediar esta situación; ii) la recaudación del impuesto sobre las transacciones financieras sería asimilable a una «cuota de seguro» para cubrir el riesgo sistémico creado por el sector financiero y que, en ocasiones origina gasto público vinculado a procesos de rescate; y iii) los ingresos impositivos podrían ser utilizados para financiar objetivos supranacionales como la asistencia al desarrollo económico o determinados bienes públicos globales (por ejemplo, mitigar el cambio climático). Así, la imposición sobre transacciones financieras puede ser una fuente de financiación de actividades deseables, que de otro modo no podrían llevarse a cabo. En el caso de la Unión Europea, la recaudación obtenida por un ITF puede sustituir parcialmente la contribución directa de los Estados miembros, convirtiéndose en una fuente propia de financiación (own resource) destinada a ciertos fines incluyendo inversiones públicas que fomentan la productividad y el empleo, así como transferencias destinadas a propósitos supranacionales tales como programas de asistencia al desarrollo.

\section{Para reducir ineficiencias que se producen en los mercados financieros}

Además de objetivos recaudatorios, la introducción de un impuesto sobre transacciones financieras se ha defendido para corregir externalidades negativas, que ocurren cuando los precios del mercado no reflejan debidamente todos los costes implicados en una determinada acción. Es decir, como un impuesto pigouviano orientado a lograr criterios de eficiencia (Contreras \& Contreras, 2015b), tal como se comenta a continuación.
Para algunos autores, un impuesto sobre transacciones financieras puede contribuir a estabilizar los mercados por ralentizar la velocidad con la que los traders reaccionan ante cambios en los precios de los activos (Erturk, 2006). Los defensores del impuesto consideran que su implantación puede reducir el exceso de liquidez derivada de un exagerado volumen de negociación de carácter especulativo y puede corregir la excesiva volatilidad de los precios de los activos. De acuerdo con los modelos de agentes heterogéneos (MAH), en los mercados financieros generalmente existen dos tipos de operadores. Los fundamentalistas basan sus expectativas sobre los precios futuros de los activos y sus estrategias de negociación en los fundamentos del mercado y en factores económicos, mientras que los chartistas realizan operaciones especulativas de corto noise trading, basadas en modelos de análisis técnico según patrones históricos de precios y cantidades (Schulmeister, 2009a). Quienes defienden el impuesto asumen que cuanto mayor es la participación de los noise traders frente a los fundamentalistas mayor es la volatilidad (Schulmeister, 2009c), ya que exhiben comportamientos excesivos de optimismo o de pesimismo. En la medida en que la euforia y el pánico vienen y se van de forma aleatoria, los precios de los activos se comportan de forma más volátil que lo que reflejaría cambios en los valores fundamentales. En opinión de estos, los robots que operan con alta frecuencia (HFT) siguiendo diferentes tipos de algoritmos también contribuyen recientemente a aumentar la volatilidad (Dow \& Gorton, 2006). En otros estudios, se distingue del mismo modo entre traders chartistas que, de forma poco racional, consideran correcta la información procedente del análisis técnico, de los analistas macroeconómicos y de analistas financieros y traders sofisticados, que son conscientes de la percepción incorrecta de los operadores chartistas respecto de la validez de la información, por lo que operan siguiendo una estrategia contramercado (Brown \& Cliff, 2001; Wang, 2001; Simon \& Wiggins, 2001; 
Sanders et al., 2000; 2003), empujando el precio de los activos hacia sus valores fundamentales (De Grauwe \& Grimaldi, 2006). En este contexto, como el efecto del impuesto sobre el coste transaccional es mayor cuanto más corto es el horizonte temporal de la transacción, los defensores de esta figura impositiva consideran que al desincentivar en mayor medida las operaciones de negociación intradía, se reduciría el efecto actual de intensificación de las tendencias de los precios, reduciéndose, por lo tanto, la volatilidad de los precios de los activos (Summers \& Summers, 1989; Palley, 2003; Schulmeister, 2009b; 2009c; 2009d; 2009e; 2009f). Un segundo tipo de modelos denominados de inteligencia cero (MCls) consideran que el comportamiento agregado de los traders, pero no así de los inversores fundamentalistas, ofrece una evolución probabilística sin ningún criterio de optimización. Esto es, operan en conjunto de forma aleatoria según los precios de mercado. En este contexto teórico, la introducción de un impuesto sobre las transacciones financieras, puede reducir la volatilidad, aunque solo si el tipo impositivo aplicado no reduce significativamente la liquidez del mercado (Farmer et al., 2005; Ehrenstein et al., 2005; Mannaro et al., 2008).

Por otra parte, se ha argumentado que se produce una situación de desaprovechamiento de recursos aplicados a la contratación en los mercados financieros, en particular, por la sobreinversión en tecnología (software e infraestructuras instalados para lograr pequeñas ventajas de información) y en capital humano dedicado al trading (Subrahmanyam, 1998; Dow \& Rahi, 2000). La especulación excesiva en el negocio financiero es una forma de búsqueda de ganancias improductiva (rent-seeking). Una actividad privadamente rentable, pero que no aumenta directamente el flujo de bienes y servicios en la economía. Se afirma que el trading a muy corto plazo es un juego de suma cero para la sociedad en su conjunto y, puesto que consume recursos, genera un coste de oportunidad y su valor añadido neto es por tanto negativo (Stiglitz, 1989).

\section{Para mitigar conductas cortoplacistas}

Algunos autores consideran que el comportamiento de agentes del mercado financiero, como analistas y traders, fomenta una visión cortoplacista por parte de los gerentes de empresas, que se ven forzados a adoptar medidas corporativas orientadas a obtener resultados en un plazo demasiado corto, en un contexto en el que las compañías cotizadas en el mercado bursátil reportan resultados de forma trimestral (Poterba \& Summers, 1995; Barton et al., 2016). Esta tendencia, además, parece haberse reforzado con el tiempo (Sampson \& Shi, 2019). Como la elevada liquidez del mercado permite a los inversores vender con bajos costes transaccionales aquellos activos que se alejan de sus valores previstos, se crea una presión constante sobre los gestores para mostrar el éxito de su gestión de forma inmediata. De esta situación se deriva un horizonte excesivamente cortoplacista en la toma de decisiones, de forma que algunas decisiones dejan de ser estratégicas para convertirse en tácticas. En este contexto, se afirma que un impuesto sobre las transacciones financieras podría reducir la frecuencia de contratación y animar a los inversores a mantener los activos financieros por períodos más largos de tiempo, lo que contribuiría a centrar la atención de los gestores en factores a largo plazo (Reinhart, 1991). Si los gestores ponen un mayor foco en la estrategia, y no en los aspectos tácticos, cabría esperar un efecto positivo a medio y largo plazo sobre la inversión y, por ende, sobre el crecimiento económico y el empleo.

\section{Para reducir el nivel de riesgo sistémico}

El impuesto sobre las transacciones financieras podría mitigar la inestabilidad en los mercados financieros y reducir la probabilidad de ocurrencia de crisis económicas desencadenadas por burbujas en activos financieros y por problemas de financiación y de iliquidez asociados al estallido de las mismas. La estabilidad financiera internacional presenta rasgos de bien 
público y el uso creciente de instrumentos derivados es motivo de preocupación para la estabilidad del sistema. Además, el avance de la negociación de instrumentos derivados (calificados como armas financieras de destrucción masiva) incentiva el apalancamiento por parte de los inversores y los agentes económicos en general. Esta circunstancia apoya la introducción de impuestos que desincentivan esta actividad (Allen \& Gale, 2000). En la misma dirección, se ha defendido que la introducción de ITF contribuiría a mitigar el efecto cascada de fondos de titulización apalancados que invierten en credit default swaps (CDS), como los collateralized loan obligations (CLOs) y los collateralized debt obligations (CDOs), vehículos de inversión que contribuyeron a amplificar los efectos de la crisis financiera que comenzó en verano de 2007 (European Commission, 2011a; 2011b; Schäfer et al., 2012).

En otro orden de cosas, se ha argumentado que la industria bancaria tiene un componente de externalidad negativa que se derrama sobre el público en general, en parte por la fragilidad ocasionada por un nivel de capital estructuralmente bajo. La actividad financiera beneficia de forma directa a aquellos que producen y consumen servicios financieros, es decir, existen efectos privados para empleados, depositantes, prestatarios e inversores de los bancos. Pero también existen costes sociales asociados al riesgo de poner en peligro a terceras personas no vinculadas a esta actividad, si se desencadena una crisis: el riesgo sistémico es un subproducto nocivo de la actividad financiera. El establecimiento de un ITF podría contribuir a internalizar estos efectos externos negativos y puede ser contemplado como una cuota de seguro para cubrir el riesgo sistémico creado por el sector financiero y para compensar el gasto público contingente en rescates bancarios (Haldane, 2010). La imposición sobre las transacciones financieras puede contemplarse como una forma de compensar la garantía implícita que ofrecen los Gobiernos al sistema bancario y que se puede traducir en costes para el contribuyente, en el caso de necesidad de rescates (European Commission, 2011b; 2013a; Vella et al., 2011). El problema del riesgo sistémico o del too big to fail consiste en que los inversores asumen esta garantía implícita como cierta, lo que genera la infraestimación de riesgos y, en definitiva, un problema de moral hazard. Ello conduce a un coste de capital requerido para el sector financiero inferior al que sería adecuado y, por tanto, un nivel de beneficios excesivos para este sector.

\section{Para mejorar los niveles de equidad vertical}

Los defensores de la imposición sobre las transacciones financieras sugieren que este impuesto, además de contribuir al logro de los objetivos de eficiencia económica, puede mejorar los niveles de equidad vertical del sistema. Consideran que el sector financiero está infragravado en comparación con otros sectores y esta discriminación fiscal favorable permite la generación de diferencias salariales positivas para empleados y directivos del sector financiero. Un ITF puede contribuir a corregir esta situación que se considera poco equitativa (Philippon \& Reshef, 2012). Además, se afirma que esta figura impositiva reforzaría el nivel de progresividad fiscal, dada la mayor proporción relativa de sujetos con renta y riqueza elevada realizando transacciones financieras. Como la propiedad de los activos financieros, particularmente en el caso de la tenencia directa de acciones pero también en el caso de su participación indirecta a través de fondos de inversión y pensiones, está fuertemente concentrada en los ricos, la introducción de impuestos sobre las transacciones financieras aumentaría la progresividad global del sistema fiscal (European Commission, 2011b). Un impuesto de esta naturaleza debería reforzar el papel redistributivo del sector público.

\section{4. ¿Por qué no deben gravarse las transacciones financieras?}

Tanto en la literatura académica, como en diversos trabajos procedentes de la industria financiera, 
encontramos también recomendaciones en contra del establecimiento de un impuesto sobre las transacciones financieras por diversos motivos.

\section{Para no deteriorar la calidad de los mercados financieros}

Las oportunidades especulativas ocurren cuando el mercado es ineficiente. El arbitraje racional de las oportunidades de lucro resulta efectivo para vaciar los mercados, estabilizar los precios, y conducir estos hacia sus valores fundamentales (Jetin \& Denys, 2005; Landau Report, 2004). Por tanto, la introducción de un impuesto sobre las transacciones financieras, lejos de mejorar la eficiencia, genera un deterioro en el funcionamiento de los mercados financieros, al reducir la liquidez y empeorar la calidad de la determinación del precio de los activos (proceso de descubrimiento de los precios). Además, aumenta los costes transaccionales al ampliarse los diferenciales entre los precios de oferta y demanda, bid-ask spread, en los mercados afectados (Frino \& West, 2003; European Central Bank, 2004). Los inversores valoran la liquidez, como lo demuestra el hecho de que exigen un menor retorno en el caso de valores muy líquidos (Amihud et al., 2005). Un mercado de valores líquido agrega valor a la economía, al ofrecer la oportunidad a empresarios y ahorradores de diversificar su riesgo. Por tanto, la introducción de un impuesto sobre las transacciones financieras que afecta negativamente al nivel de liquidez, tendrá un impacto negativo sobre el nivel de bienestar social.

El rechazo a la introducción de un impuesto sobre las transacciones financieras se apoya también en la consideración de que resulta imposible diseñar una figura tributaria con capacidad para reducir de forma selectiva la actividad de un tipo de operador en particular. Un ITF no puede discriminar su efecto sobre la negociación fundamental o sobre el ruido. Reducir la actividad de operaciones que transmiten información fundamental valiosa y que, por tanto, contribuyen a conducir los precios hacia sus valores fundamentales, tendrá un impacto negativo (Hakkio, 1994; Habermeier \& Kirilenko, 2003; Hommes, 2006; Keen, 2011; Vella et al., 2011; Anthony et al., 2012).

Además, los críticos del establecimiento de impuestos sobre las transacciones financieras destacan que las oscilaciones en el precio de los activos financieros no necesariamente provienen de operaciones especulativas desestabilizadoras, sino que pueden ser reflejo de la variabilidad observada en los fundamentos económicos que determinan su valor (Friedman, 1953).

También se ha argumentado que el impacto de la reducción de la liquidez sobre la volatilidad del precio de los activos depende de la microestructura de mercado y la composición relativa de operadores que generan ruido y de inversores fundamentalistas (Haberer, 2004; Song \& Zhang, 2005; Dow \& Gorton, 2006; Shi \& Xu, 2009), de modo que el impuesto puede ser neutral respecto del nivel de volatilidad (Bloomfield et al., 2009; Foucault et al., 2011; Buss et al., 2011). Y si se produce una reducción de la negociación ejecutada por los agentes mejor informados en mayor medida que lo hace la contratación de los agentes especuladores, podría producirse un incremento de la volatilidad de los precios (Song \& Zhang, 2005; Ehrenstein et al., 2005; Mannaro et al., 2008; Pellizzari \& Westerhoff, 2009). Se han identificado, adicionalmente, otros factores que podrían poner en duda el impacto estabilizador de un impuesto sobre las transacciones financieras en el nivel de volatilidad. El impacto de los costes transaccionales en la liquidez afecta de forma diferente a la volatilidad de los precios, dependiendo del escenario y del nivel de eficiencia del mercado. Puede existir una relación en forma de $U$ entre liquidez y exceso de volatilidad. En contextos de mercados ineficientes, una mayor liquidez reduce el exceso de volatilidad a diferencia de lo que pasa en un escenario de gran volumen de contratación. Un impuesto sobre las transacciones financieras en un escenario de liquidez reducida puede aumentar el carácter volátil de los precios (Haberer, 2004). 
Además, el efecto de introducir un ITF podría conducir a un aumento de la inestabilidad en mercados organizados en forma de doble subasta continua, a diferencia de lo que ocurriría en los mercados organizados en torno a dealers (Pellizari \& Westerhoff, 2009). Por otra parte, el impacto del impuesto sobre la volatilidad es diferente en un ciclo alcista o bajista (Dupont \& Lee, 2007). Y su efecto sobre el exceso de volatilidad de los precios puede depender también de la magnitud del tipo impositivo. A partir de una determinada tasa cabe esperar un aumento en la volatilidad (Farmer et al., 2005; Demary, 2010). Finalmente, en los modelos que utilizan un enfoque de teoría de juegos (MTJs) y en estudios con un enfoque experimental, la relación entre costes transaccionales y exceso de volatilidad se asocia al tamaño del mercado y sus características en términos de eficiencia informacional. Así, la introducción de un ITF puede acentuar el perfil volátil de los precios en mercados pequeños o que se encuentran en la zona crítica de eficiencia informacional (Kaiser et al., 2007; Hanke et al., 2010).

\section{Para no generar ineficiencia económica}

Incluso si el sector financiero estuviera infragravado en comparación con otros sectores y fuera deseable corregir esta situación, los críticos del impuesto sobre transacciones financieras dudan que esta opción sea la menos distorsionante. Resulta difícil gravar las transacciones financieras si no se trata de un impuesto a nivel internacional global y uniforme, ya que es relativamente sencillo diseñar esquemas orientados a transferir operaciones a otros mercados nacionales o internacionales no gravados, o bien crear operaciones equivalentes no gravadas. Aquellos que desaconsejan la introducción de un ITF destacan sus efectos negativos sobre la eficiencia económica. Efectos que se producen, básicamente, por una alteración en la correcta asignación del capital y del riesgo en la actividad productiva. Entre los factores por los que este impuesto genera ineficiencia destacan: su desincentivo al comercio internacional (Nissanke,
2004) y la reducción de los flujos internacionales de capital, lo que implica también una asignación subóptima de los recursos a nivel global (Campbell \& Froot, 1994). Además, la introducción de ITF implica relocalizaciones ineficientes de la actividad financiera entre plazas (efecto de deslocalización fiscal) con un impacto negativo sobre el bienestar social global (Umlauf, 1993; Campbell \& Froot, 1994; Reisen, 2002; Chou \& Wang, 2006; Xu, 2010; Vella et al., 2011; Davis et al., 2013; Oxera Consulting, 2014a). Se argumenta, por otra parte, que el impuesto sobre transacciones financieras resulta poco neutral al afectar de forma diferente a las compañías según su forma de financiación y su distinto nivel de liquidez en bolsa (Amihud et al., 2005; Habermeier \& Kirilenko, 2003; Grahl \& Lysandrou, 2003). Además, de acuerdo con los resultados de análisis económico, los impuestos sobre transacciones intermedias son más distorsionadores que aquellos otros que gravan las transacciones finales y, por tanto, deben evitarse (Diamond \& Mirrlees, 1971). Adicionalmente, al reducir la rentabilidad financiera de los activos afectados, este impuesto altera las decisiones óptimas de ahorro, de forma positiva o negativa según la magnitud relativa de los efectos renta y sustitución. Esta circunstancia afecta negativamente a la eficiencia económica (McCrae, 2002; Li, 2009; Davis et al., 2013; City of London, 2014; Oxera Consulting, 2014a). Y si el impuesto recae también sobre la negociación de instrumentos derivados, la actividad de cobertura de riesgos de mercado y de crédito se verá negativamente condicionada y, por ende, distorsionada la asignación de los recursos (Grahl \& Lysandrou, 2003; Oxera Consulting, 2014a). En el mismo sentido, la introducción de un impuesto sobre las transacciones financieras produce ineficiencia al distorsionar la recomposición óptima de cartera, como consecuencia de la ampliación de la zona en la que los costes de transacción compensan los beneficios de dicha recomposición, lo que se conoce como no trade zone (Constantinides, 1986). El impuesto amplía el efecto de cierre, lock-in, que se deriva del impuesto sobre ganancias de capital (Dammon \& Spatt, 1996). 


\section{Porque el impuesto se traslada a ahorradores y clientes finales}

Aunque los sujetos pasivos del impuesto sobre transacciones financieras son las entidades financieras, existe consenso en que es posible la traslación de la carga impositiva hacia sus clientes finales (efecto incidencia). En el caso de la actividad de brokerage, las comisiones aumentarán ya que la estructura de este negocio les impide absorber el gravamen y, en general, por el efecto cascada del impuesto (Vella et al., 2011; Vella, 2012). Por otra parte, la introducción de un impuesto sobre transacciones financieras tiene un impacto negativo en la rentabilidad anual de instrumentos de inversión más relevantes mantenidos por las familias: fondos de inversión, fondos de pensiones e instrumentos de ahorro-seguro. Desde el momento mismo de la introducción del impuesto, se produce una devaluación de las posiciones de estos vehículos por un efecto capitalización negativo que genera a su vez un efecto riqueza contractivo sobre el consumo (Case et al., 2005; Carroll et al., 2011). Además, en la medida que el impuesto sobre transacciones financieras implica un encarecimiento de la financiación bancaria con bonos, dado el creciente recurso del sistema crediticio a los mercados de capitales, el margen de la actividad bancaria se reduce. $\mathrm{Y}$, por el efecto incidencia, este impacto eleva los diferenciales de crédito de los préstamos concedidos por bancos a familias y empresas. En consecuencia, el encarecimiento de la financiación a los clientes finales causado por el impuesto tendría, a su vez, un impacto negativo en la inversión tanto en capital productivo como en activos inmobiliarios.

\section{Porque la recaudación neta puede ser poco relevante}

En la práctica, la recaudación neta obtenida de un impuesto sobre transacciones financieras, aunque previsiblemente positiva, suele ser menos relevante de lo inicialmente considerado. En consecuencia, difícilmente sirve para compensar los costes potenciales para el sector público asociados a la ejecución de rescates bancarios. La recaudación bruta del impuesto se ve significativamente reducida por: i) los mayores costes de financiación del Gobierno derivados del gravamen de sus emisiones en el mercado secundario (si este instrumento no queda exento); ii) la pérdida parcial de recaudación en los impuestos sobre la renta personal y los beneficios societarios, como consecuencia de posibles efectos negativos de segunda ronda sobre los rendimientos y ganancias de capital obtenidos por entidades y familias (Davis et al., 2013); iii) la existencia de costes directos de organización, administración, control e inspección asociados a la gestión del impuesto; iv) comportamientos de evasión fiscal y de elusión fiscal vía generación de nuevos tipos de transacciones no sujetas en un entorno de globalización financiera (Brondolo, 2011).

\section{Porque no es el mejor impuesto para reducir el nivel de riesgo sistémico}

Los críticos del impuesto sobre transacciones financieras rechazan que este tributo resulte particularmente útil para reducir la inestabilidad financiera y el riesgo sistémico, ya que no opera sobre una variable determinante del nivel de riesgo que aporta cada entidad (Anthony et al., 2012; IMF, 2010). La base imponible de este impuesto no es una variable que aproxime bien el riesgo asumido por las entidades bancarias, a diferencia de lo que ocurre, por ejemplo, con el nivel de VAR (value at risk). Además, si una de las causas de la crisis financiera fue el desarrollo de $\mathrm{CDOs}^{2}$ (Collateralized Debt Obligation Squared) en los que los activos de un vehículo de titulización son a su vez el capital y/o los tramos subordinados de otros $\mathrm{CDOs}^{2}$, la introducción de un impuesto sobre transacciones financieras no hubiera contribuido significativamente a reducir su proliferación, ya que al ser inversiones de largo plazo se ven menos afectadas por este impuesto (Honohan \& Yoder, 2011). 


\section{Porque no es fácil coordinar el uso de los recursos fiscales}

Los defensores del impuesto sobre transacciones financieras ponen énfasis en la posibilidad de utilizar la recaudación derivada de su implantación para financiar bienes públicos globales. Sin embargo, los críticos del impuesto resaltan que resultará difícil alcanzar acuerdos supranacionales entre países, dada la importante concentración geográfica de las transacciones financieras en pocos centros financieros. En la práctica, el nivel de actividad financiera se encuentra en Europa muy concentrada en las plazas de Paris, Frankfurt y, particularmente, de Londres. Por tanto, será complicado que los países más afectados por el impuesto ofrezcan la recaudación obtenida para financiar este tipo de bienes que, por su propia naturaleza, son no excluibles en el consumo. El reparto de la cuota contributiva resultará objeto de acuerdos complicados (Schulmeister et al., 2008; Darvas \& Von Weizsäcker, 2010).

\section{Porque la mejora del nivel de equidad es discutible}

Si el impuesto sobre transacciones financieras pretende mejorar la justicia social, compensar los efectos derivados de los rescates bancarios, y corregir la sobrerrentabilidad del sector en el período previo a la crisis, o finalmente afectar negativamente a los gestores responsables de la crisis, se ha señalado que introducir este impuesto no resulta lo más práctico por diversas razones. Estos rescates no se diseñaron para salvar a los accionistas de los bancos, sino para evitar que se desencadenara una espiral de crisis y quiebras bancarias, y también para rescatar a los clientes minoristas tenedores de los depósitos bancarios. Desde esta perspectiva, no tiene sentido castigar a los actuales accionistas de las entidades tras los procesos de bail-out (que se articularon en forma de inyecciones de capital y suscripción de participaciones convertibles por parte del sector público), ya que los accionistas en el momento de los rescates experimentaron su coste en forma de diluciones masivas y pérdida muy elevada del valor de sus acciones (Vella et al., 2011). Además, si el impuesto sobre transacciones financieras se introduce con el objetivo de compensar un exceso de rentabilidad obtenida por los accionistas del sector antes de la crisis, que se derivó de la existencia de una garantía implícita vinculada a situaciones de too-big-to-fail (TBTF), aquellos ya abandonaron previsiblemente la escena, o bien perdieron su capital por la masiva devaluación de sus posiciones en acciones. La introducción de este impuesto afectaría a los actuales accionistas en forma de una depreciación inmediata de sus carteras de acciones bancarias por el efecto capitalización. Adicionalmente, si el objetivo del impuesto es castigar a los gestores responsables de la crisis financiera, se ha indicado que este impuesto no puede discriminar entre entidades que fueron mejor o peor gestionadas en el período previo a la crisis. Además, la mayor parte de estos gestores previsiblemente ya abandonaron sus puestos de responsabilidad. También se ha señalado que establecer un impuesto sobre transacciones financieras esperando gravar las entidades rescatadas no tiene sentido, desde la perspectiva presupuestaria si estas son todavía en cierta medida propiedad del sector público. Al menos en el caso de Europa, una parte del capital de las entidades rescatadas permanece en carteras de agencias públicas, por lo que si los bancos no trasladan la carga impositiva, la introducción del impuesto implicaría una pérdida de valor de los activos del sector público $y$, en consecuencia, de todos los contribuyentes. Y si, por el contrario, los bancos logran trasladar su carga impositiva, la reducción de la utilidad la experimentarían los contribuyentes en su conjunto (empresas y familias) dado el alto nivel de bancarización en los países desarrollados.

Finalmente, reforzar el nivel de progresividad del sistema, gravando transacciones que se concentran en mayor media en sectores sociales de alta renta y elevado patrimonio, puede implicar ganancias en 
términos de equidad. Sin embargo, esto ocurrirá previsiblemente a costa de un deterioro en el nivel de eficiencia económica, como la teoría de la imposición óptima se ha ocupado de mostrar. Así, acentuar el nivel de progresividad del sistema con impuestos sobre las transacciones financieras, no es necesariamente óptimo cuando se contemplan simultáneamente criterios de equidad y eficiencia.

\section{Evidencia empírica sobre los efectos del ITF}

Cinco cuestiones han centrado la atención empírica sobre los efectos de introducir un impuesto sobre las transacciones financieras: i) la conexión entre el nivel de costes transaccionales y el volumen de negociación en los mercados financieros; ii) la pérdida de liquidez del mercado asociada al incremento de los costes transaccionales; iii) la relación entre el volumen de negociación y la volatilidad del precio de los activos; iv) el fenómeno de deslocalización fiscal de la actividad financiera; y $v$ ) el nivel de recaudación. Adicionalmente, otros análisis han revisado también los efectos del impuesto sobre: i) la rentabilidad de los activos gravados; ii) el mayor coste en las coberturas de riesgos; iii) el encarecimiento de la financiación bancaria y corporativa; y iv) la traslación de la carga impositiva desde los sujetos pasivos a los inversores y a los clientes bancarios.

Sobre la cuestión del impacto de los costes de transacción en el nivel de contratación, los estudios empíricos (que se han basado tanto en análisis de series temporales como en datos de panel) asimilan el incremento en el coste transaccional derivado de un aumento, por motivos regulatorios, en el tamaño de los ticks con la introducción de impuestos sobre transacciones que implique el mismo incremento en el diferencial entre precios de oferta y demanda. Estos estudios ofrecen consenso sobre la relación negativa entre ambos eventos, pero no son concluyentes respecto de su magnitud. Entre los estudios más recientes véase Aitken y Swan (2000), Swan y Westerholm
(2001), Zhang (2001), Baltagi et al. (2006), Chou y Wang (2006), Liu (2007) y Schmidt (2007).

En el caso del impuesto francés sobre acciones, los resultados indican una caída de aproximadamente una quinta parte en la contratación respecto del período preimpuesto. Si bien el impacto sobre la contratación derivada de la provisión de liquidez es leve, como consecuencia de la exención en esta actividad, la negociación off-exchange disminuyó en un 40 \%, y las grandes operaciones OTC prácticamente desaparecieron (Colliard \& Hoffmann, 2013). Además, los proveedores de liquidez redujeron el número de actualizaciones de cotizaciones y se registró un volumen inferior en las posiciones a los mejores precios por el efecto del impuesto (Becchetti et al., 2014; Meyer et al., 2015; Capelle-Blancard \& Havrylchyk, 2016). También se evidenció un incremento en los diferenciales entre los precios de oferta y demanda en las posiciones, indicando una reducción en el nivel de liquidez y de calidad del mercado bursátil tras la implementación del impuesto (Haferkorn \& Zimmermann, 2013; Šramko, 2015). Otros estudios tampoco encuentran apoyo a la idea de que un ITF mejore la calidad del mercado al afectar a la composición del volumen de negociación, aunque documentan un cambio en las tenencias de valores desde inversores a corto plazo a los de largo plazo (Colliard \& Hoffmann, 2017). Por el contrario, se estima un deterioro de la calidad del mercado que amenaza la transmisión de información entre los fragmentados mercados europeos (Haferkorn \& Zimmermann, 2013; Gomber et al., 2016). Para el caso del impuesto italiano sobre transacciones bursátiles, la evidencia empírica es similar. Se aprecia una pérdida de liquidez y calidad de mercado (Šramko, 2015) y una elevación importante de los costes transaccionales (Hvozdyk \& Rustanov, 2016).

La evidencia respecto del impacto de los impuestos sobre transacciones financieras sobre la volatilidad de los precios de los activos financieros es menos concluyente. Los análisis econométricos ofrecen resultados opuestos dependiendo de los modelos especificados, del tipo de variación o shock analizado y del 
período de la muestra considerado. Entre los trabajos recientes que ofrecen una relación negativa entre costes transaccionales y volatilidad de los precios se encuentran los de Hau (2001), Huang et al. (2002), Sarwar (2003), Liu y Zhu (2009), Su y Zheng (2011) y Becchetti et al. (2014). Numerosos estudios muestran, sin embargo, una relación ambigua o poco significativa, como es el caso de Saporta y Kan (1997), $\mathrm{Hu}$ (1998), Bessembinder y Rath (2002), Chou y Wang (2006), Phylaktis y Aristidou (2007), Šramko (2015), Capelle-Blancard y Havrylchyk (2016), o Hvozdyk y Rustanov (2016). En contra del argumento de que introducir un impuesto sobre transacciones financieras contribuiría a reducir la volatilidad de los precios de los activos gravados, un conjunto de trabajos empíricos indican incluso la existencia de una relación positiva entre variaciones en los costes transaccionales y cambios en la volatilidad de mercado, como por ejemplo Green et al. (2000), Aitken y Swan (2000), Domowitz et al. (2001), Wang y Yau (2000), Swan y Westerholm (2001), Bessembinder y Rath (2002), Aliber et al. (2003), Hau (2006), Baltagi et al. (2006) y Lanne y Vesala (2010). En definitiva, no existen resultados empíricos concluyentes respecto del signo y la magnitud del impacto de los impuestos sobre transacciones financieras en la volatilidad del precio de los activos. Se han expuesto ciertas debilidades metodológicas en los trabajos empíricos relacionadas con: $i$ ) problemas de comparabilidad, al utilizar los estudios diferentes medidas de volatilidad; ii) la imposibilidad de separar el efecto del impuesto sobre las transacciones financieras de otros cambios estructurales y políticos, que pueden tener lugar al mismo tiempo; y iii) la dificultad para identificar la magnitud de las transacciones basadas en criterios fundamentales de aquellas otras basadas en criterios especulativos - véase Schulmeister et al. (2008) y McCullock y Pacillo (2011)_. En relación con la primera cuestión, diferentes estudios han utilizado al menos tres medidas diferentes: i) la volatilidad estadística de corto plazo (calculada como la desviación estándar en base de datos de cierre diarios); ii) la volatilidad fundamental a corto plazo (calculada como la varianza del rendimiento de los activos con respecto a la varianza de sus fundamentos), que refleja la velocidad del proceso de incorporación de nueva información sobre el valor fundamental al mercado; y iii) el exceso de volatilidad o sobrerreacción a largo plazo, que mide las oscilaciones del precio de los activos en torno a su nivel de equilibrio fundamental a largo plazo (Kupiec, 1996). Para los defensores del impuesto resulta más preocupante el impacto sobre la volatilidad a largo plazo, ya que las burbujas financieras y su posterior estallido presentan externalidades macroeconómicas más graves. Pero, en este sentido, los críticos del impuesto señalan que los costes transaccionales no parecen jugar un papel determinante. Las burbujas son comunes en el mercado inmobiliario, donde los costes de transacción son muy altos en comparación con los de los mercados financieros, lo que sugiere que la introducción de un impuesto sobre transacciones financieras difícilmente impedirá que se generen burbujas en los mercados de activos financieros. Desde esta perspectiva, para prevenir burbujas en los precios de los activos, un medio más directo consistiría en desincentivar las compras apalancadas, aumentando los requerimientos de garantías y los margin call, en particular durante la fase ascendente del ciclo de mercado.

Por lo que respecta al ITF diseñado en el ámbito de la Unión, se han estimado otros potenciales efectos. En concreto, se espera un impacto negativo anual en la rentabilidad de los fondos de inversión y de los fondos de pensiones para los inversores individuales de los Estados miembros participantes en un rango entre 10 mil y 15 mil millones de euros, mientras que se trasladaría un coste anual hacia los usuarios finales de los Estados por un importe entre 15 mil y 30 mil millones de euros. Además, se incrementaría el coste anual de las coberturas en un rango entre mil y 3 mil millones de euros para el conjunto de las empresas de los Estados participantes (Davis et al., 2013). Por otra parte, se ha estimado que el impuesto elevaría el 
coste de la financiación bancaria mediante su recurso a los mercados de capital, en torno al 0,036 \% (Oxera Consulting, 2014a). Y en lo que respecta a la financiación corporativa, el potencial efecto negativo sobre la liquidez derivado de la introducción del impuesto sobre transacciones financieras, de acuerdo con algunos estudios podría implicar un incremento del coste de financiación mediante bonos y capital de unos 40 puntos básicos (Oxera Consulting, 2012; 2014a; 2014b). Adicionalmente, otros estudios indican un coste anual estimado entre 7 mil y 8 mil millones de euros, o entre 10 y 20 puntos básicos de coste adicional, por el encarecimiento de la financiación en las emisiones de las empresas de los Estados Miembros Participantes (véase Davis et al., 2013). Otras estimaciones ofrecen como resultado un incremento esperado de entre 4 o 5 puntos básicos en el coste de capital de las empresas, lo que podría implicar una reducción de aproximadamente un 0,2 \% en el stock de capital (Lendvai et al., 2012). Este encarecimiento de la inversión empresarial podría además traducirse en un empeoramiento de los datos macroeconómicos en términos de la formación bruta de capital (Schwert \& Seguin, 1993; Bond et al., 2005; Block, 2007; Matheson, 2011).

En otro orden de cosas, respecto de los efectos colaterales de la introducción del impuesto sobre transacciones financieras en el presupuesto público, se ha estimado un incremento medio de los costes de financiación por parte del sector público en la zona de implantación del impuesto del 0,4 \% (Oxera Consulting, 2014a). Otras estimaciones indican, en el mismo sentido, un impacto en términos de mayor coste anual de financiación en un rango entre 15 mil y 20 mil millones de euros (Davis et al., 2013). También en relación con el impacto en el cumplimiento presupuestario, la pérdida de recaudación asociada al impacto negativo derivado de la introducción del ITF en las bases imponibles de los impuestos sobre la renta personal y de sociedades, en el caso de los Estados miembros participantes, se ha estimado en 22 mil millones de euros anuales (Oxera Consulting, 2014a).
Finalmente, en relación con los efectos del impuesto sobre las transacciones financieras en el nivel de eficiencia económica, se ha afirmado que en los países que establecieran el impuesto se produciría, por el efecto riqueza, un impacto negativo sobre el consumo y una reducción en la tasa de crecimiento del PIB. En particular, algunos estudios indican una reducción de entre un $0,5 \%$ y un $0,9 \%$ en el nivel de PIB europeo a largo plazo en precios constantes (City of London, 2014). Otros estudios han estimado un efecto contractivo sobre el PIB derivado del impuesto de un 0,6 \% en los Estados miembros participantes (Oxera Consulting, 2014a), mientras que el modelo dinámico de equilibrio general (DSGE) de la CE estima una caída del PIB del 1,67 \% a largo plazo (European Commission, 2011a; 2013b).

\section{Estimación del impacto sobre la liquidez en el mercado español}

En este apartado se aborda la cuestión del impacto del impuesto sobre transacciones bursátiles en la liquidez del mercado. Por lo que respecta a la metodología para realizar este análisis, cuando un impuesto lleva en vigor un período temporal suficiente, un método que ha ido ganando adeptos para estimar su impacto sobre la contratación y la liquidez del mercado es el denominado Difference-in-difference o DiD (Imbens \& Wooldridge, 2009). Con este método se observan resultados para dos grupos y dos períodos de tiempo. Hay un grupo A expuesto a una determinada política (por ejemplo, un impuesto sobre las transacciones bursátiles) en el segundo período pero no en el primero. El segundo grupo $\mathrm{B}$ o de control no está expuesto al efecto en ninguno de los dos períodos (por ejemplo, transacciones sobre acciones no sujetas). Se comparan los resultados del grupo A antes y después de la intervención política. La media de los cambios en la variable observada del grupo de control $B$ se resta de la media del cambio en el grupo expuesto A. De este modo, se eliminan los sesgos en las comparaciones 
del segundo período entre el grupo de tratamiento y el de control, que podrían ser el resultado de diferencias permanentes entre esos grupos, así como los sesgos de las comparaciones a lo largo del tiempo en el grupo expuesto a la política, que podrían ser el resultado de determinadas tendencias (Wooldridge, 2007). También se pueden utilizar dos grupos de control. Por ejemplo, si el ITF español estuviera en vigor, un grupo de control incluiría empresas pequeñas, o con un nivel de capitalización inferior a 1.000 millones de euros. Y un segundo grupo de control correspondería a empresas grandes pero no españolas.

Un segundo método es el enfoque Agent-Based Modeling ( $\mathrm{ABM})$, de acuerdo con el cual: se desarrolla un mercado financiero artificial; se define una forma de comportamiento de los agentes; se identifican los parámetros de la microestructura de mercado; se realiza una simulación de comportamiento con diferentes parámetros en torno a valores razonables de mercado; y se comparan los resultados procedentes de un escenario con impuesto y un escenario de control para obtener conclusiones. Se trata de un enfoque computacional. Cuando, como es el caso español, el impuesto cuyo efecto se quiere analizar no está en vigor, este es el enfoque disponible. Las hipótesis utilizadas en relación al comportamiento de mercado pueden apoyarse en analogías respecto de lo ocurrido en otros mercados (por ejemplo, el caso francés o italiano) o en encuestas realizadas a agentes del mercado español. El trabajo de Contreras (2019), que utiliza un modelo ABM con datos para el período de un año (entre noviembre de 2018 y noviembre de 2019), considera una acción sintética creada como media del conjunto de los diez valores del IBEX con mayor capitalización ${ }^{8}$. De acuerdo con los datos ponderados de estos valores, esta acción sintética se caracterizaría por un retorno anual del 6,7 \%, una volatilidad anualizada del $20,72 \%$ y un diferencial entre precios de

\footnotetext{
8 Inditex, Iberdrola, Banco Santander, Telefónica, Amadeus, BBVA, Endesa, Aena, Repsol y Naturgy.
}

oferta y demanda de 5 puntos básicos. Se considera que el valor de esta acción sigue un movimiento browniano tal que $d \ln A_{t}=\mu d t+\sigma d W_{t}$, donde $\mu$ representa el crecimiento medio en cada período, $\sigma$ es la volatilidad del crecimiento y $W_{t}$ es un proceso de Wiener tal que sus trayectorias son continuas, sus incrementos (no solapados) son independientes, $W_{0}=0 ;$ y $W_{t}-W_{s}$ es una variable gaussiana con media cero y varianza t-s. Es decir $W_{t}-W_{s} \rightarrow N(0, t-s)$. El valor medio de la distribución de valores de la acción en el período $t$ viene dado por $A_{t}^{e}$ tal que:

$$
A_{t}^{e}=A_{o} e^{\left(\mu+\frac{\sigma^{2}}{2}\right) t}
$$

La probabilidad incondicionada de que el valor de $A_{t}<A_{t}^{e}$ viene dada por:

$$
p_{t}=N\left(\frac{\sigma \sqrt{t}}{2}\right)
$$

En el modelo se considera que un trader, que tiene cierta información que le permite asignar una probabilidad condicionada a los escenarios de subida $\left(A_{t}^{+}\right)$y bajada $\left(A_{t}^{+}\right)$del valor, se plantea una estrategia en la que abre una posición y espera cerrarla en un determinado plazo. La introducción del ITF perjudica el retorno de la transacción ${ }^{9}$ y, para cada tipo impositivo, el impacto sobre el retorno de la transacción es mayor cuanto menor sea el horizonte temporal de la estrategia. Las principales conclusiones indican que es previsible que desaparezcan casi al $100 \%$ las estrategias de inversión entre uno y tres días. La actividad procedente de estrategias a plazos superiores puede reducirse significativamente dependiendo de la asignación interna de costes y riesgos y bajo reglas de decisión

\footnotetext{
9 El retorno viene definido por:

$$
r^{\prime \prime}(())=\frac{1}{t} \ln \frac{\left[p_{t}^{\prime} A_{t}^{+}+\left(1-p_{t}^{\prime}\right) A_{t}^{*}\right] e^{-\rho t}\left(1-\frac{s}{2}\right)}{A_{0}\left(1+\frac{s}{2}\right)(1+\tau)}
$$

donde $s$ es el diferencial de oferta y demanda y $r$ es el tipo impositivo. 
que implicasen no abrir posiciones cuando el retorno esperado es positivo pero significativamente menor al que se produce en ausencia del impuesto. El impacto total sobre la negociación bursátil dependerá esencialmente de la distribución actual de estrategias por plazos.

En otro orden de cosas, para el ejercicio 2019, había 58 compañías españolas con acciones sujetas al impuesto por tener una capitalización superior a 1.000 millones de euros. El importe de negociación en SIBE (BME) fue de unos 438.000 millones de euros. Bajo la hipótesis de que un $40 \%$ de la contratación se produce en plataformas electrónicas ${ }^{10}$, se considera un nivel de negociación de 730.000 millones de euros. Considerando un tipo impositivo del 0,20\% implica que la previsión de recaudación del Gobierno asume una reducción de la contratación cercana al $42 \%$, incluyendo la caída de negociación por cambios en el comportamiento, behavioral effect, por elusión fiscal vía sustitución de instrumentos gravados por no gravados y por deslocalización fiscal.

\section{Comentarios finales}

En el ámbito europeo, Francia e Italia, y a partir del año 2021 España, han introducido de forma unilateral impuestos sobre las transacciones bursátiles. Mientras, en la Unión Europea la implantación de un impuesto general sobre transacciones financieras impulsado por diez Estados miembros está estancado. Este tipo de impuestos son muy controvertidos. Algunos esperan de su implantación un incremento significativo en los ingresos fiscales, una reducción de la actividad especulativa y en la volatilidad en el precio de los activos, así como una mejora en términos de equidad vertical. Por el contrario, sus detractores atribuyen al impuesto un impacto negativo en la eficiencia económica y una significativa reducción en la liquidez de

\footnotetext{
10 Entre las que destacan: BATS Global Markets (CBOE Holdings Inc), Chi-X, Aquis Exchange PLC o Turquoise (London Stock Exchange Group).
}

mercado, acompañada de una recaudación decepcionante. Además, el riesgo de deslocalización fiscal de la actividad bursátil resulta evidente.

\section{Referencias bibliográficas}

Aitken, M. \& Swan, P. (2000). The Impact of a Transaction Tax on Security Market Traders: The Case of Australia's Tax Reduction. Working Paper, University of Sydney.

Aliber, R. Z., Chowdhury, B. \& Yan, S. (2003). Some evidence that a Tobin tax on foreign exchange transactions may increase volatility. European Finance Review, 7(3), 481-510.

Allen, F. \& Gale, D. (2000). Bubbles and Crises. The Economic Journal, 110(460), 236-255.

Amihud, Y., Mendelson, H. \& Pedersen, L. H. (2005). Liquidity and asset prices. Foundation and Trends in Finance, 1(4), 1-96.

Anthony, J., Bijlsma, M., Elbourne, A., Lever, M. \& Zwart, G. (2012). Financial transaction tax: review and assessment. CPB the Netherlands Bureau for Economic Policy Analysis Discussion Paper, 202.

Autoridad Independiente de Responsabilidad Fiscal (AIReF) (2018). Informe sobre las Líneas Fundamentales de los Presupuestos de las Administraciones Públicas 2019. Informe 45/18.

Baltagi, B. H., Li, D. \& Li, Q. (2006). Transaction tax and stock market behavior: Evidence from an emerging market. Empirical Economics, 31(2), 393-408.

Barton, D., Bailey, J. \& Zoffer, J. (2016). Rising to the challenge of short-termism. Focusing Capital on the Long Term. FCLT Global.

Becchetti, L., Ferrari, M. \& Trenta, U. (2014). The impact of the French Tobin tax. Journal of Financial Stability, 15, 127-148.

Bessembinder, H. \& Rath, S. (2002). Trading Costs and Return Volatility: Evidence from Exchange Listings. Working Paper, Utah: University of Utah.

Block, S. (2007). The liquidity discount in valuing privately owned companies. Journal of Applied Finance, 17(2), 33-40.

Bloomfield, R., O'Hara, M. \& Saar, G. (2009). How Noise Trading Affects Markets: An Experimental Analysis. Review of Financial Studies, 22(6), 2275-2302.

Bond, S., Hawkins, M. \& Klemm, A. (2005). Stamp duty on shares and its effect on share prices. Institute for Fiscal Studies Working Paper 04/11.

Brondolo, J. D. (2011). Taxing Financial Transactions: An Assessment of Administrative Feasibility. IMF Working Paper, No $11 / 185$.

Brown, G. W. \& Cliff, M. T. (2001). Investor sentiment and the near term stock market. In Financial Economics Network, Capital Markets Abstracts: Market Efficiency. Working paper, 
Kenan-Flagler Business School. University of North Carolina-Chapel Hill.

Buss, A., Uppal, R. \& Vilkov, G. (2011). Asset Prices in General Equilibrium with Transactions Costs and Recursive Utility. Working Paper EDHEC-Risk y Goethe University.

Campbell, J. Y. \& Froot, K. (1994). International experiences with security transaction taxes. In J. Franker (ed.), The Internationalization of Equity Markets (pp. 277-308). University of Chicago.

Capelle-Blancard, G. \& Havrylchyk, O. (2016). The impact of the French securities transaction tax on market liquidity and volatility. International Review of Financial Analysis, 47, 166-178.

Carroll, C. D., Otsuka, M. \& Slacalek, J. (2011). How Large Are Housing and Financial Wealth Effects? A New Approach. Journal of Money, Credit and Banking, 43(1), 55-79.

Case, K. E., Quigley, J. M. \& Shiller, R. J. (2005). Comparing Wealth Effects: The Stock Market versus the Housing Market. The B.E. Journal of Macroeconomics, 5(1).

Chou, R. K. \& Wang, G. H. (2006). Transaction tax and market quality of the Taiwan Stock Index Futures. Journal of Futures Markets, 26(12), 1195-1216.

City of London (2014). The effects of a Financial Transaction Tax on European households' savings. Special Interest Paper City of London Corporation.

Coelho, M. (2016). Dodging Robin Hood: Responses to France and Italy's Financial Transaction Taxes. https://ssrn.com/ abstract $=2389166$

Colliard, J. E. \& Hoffmann, P. (2013). Sand in the Chips? Evidence on Taxing Transactions in Modern Markets. Social Science Research Network Working Paper.

Colliard, J. E. \& Hoffmann, P. (2017). Financial Transaction Taxes, Market Composition, and Liquidity. The Journal of Finance, 72(6), 2685-2716.

Constantinides, G. M. (1986). Capital market equilibrium with transaction costs. Journal of Political Economy, 94(4), 842-862.

Contreras, C. (2019, 21 de noviembre). ¿Cómo afecta la imposición sobre las transacciones financieras a la liquidez del mercado? FEDEAWorkshop sobre los Retos de la Fiscalidad en la Era Digital.

Contreras, C. \& Contreras, M. (2015a). Estimación de la recaudación del Impuesto sobre Transacciones Financieras: el caso español. Hacienda Pública Española / Review of Public Economics, 213(2), 109-143.

Contreras, C. \& Contreras, M. (2015b). El impuesto general sobre transacciones financieras como impuesto Pigouviano: introducción a una controversia. Revista Análisis Financiero, Instituto Español de Analistas Financieros, (127), 1-33.

Contreras, C. \& Contreras, M. (2018). El impuesto sobre transacciones financieras: ¿Debe establecerse? Editorial Académica Española.
Dammon, R. M. \& Spatt, C. S. (1996). The optimal trading and pricing of securities with asymmetric capital gains taxes and transaction costs. Review of Financial Studies, 9(3), 921-952.

Darvas, Z. \& Von Weizsäcker, J. (2010). Financial transaction tax: Small is beautiful. Corvinus University of Budapest Working Paper No 1.

Davis, J., Smith, B., Wagner, M. \& O’Kelly, R. (2013). The impact of the EU-11 Financial Transaction Tax on end-users. Oliver Wyman (Financial Services).

De Grauwe, P. \& Grimaldi, M. (2006). Exchange rate puzzles: A tale of switching attractors. European Economic Review, 50(1), 1-33.

Demary, M. (2010). Transaction taxes and traders with heterogeneous investment horizons in an agent-based financial market model. Economics: The open-access, open-assessment, E-Journal, 4, 1-44.

Diamond, P. A. \& Mirrlees, J. A. (1971). Optimal taxation and public production I: Production efficiency. American Economic Review, 61(1), 8-27.

Domowitz, I., Glen, J. \& Madhavan, A. (2001). Liquidity, volatility and equity trading costs across countries and over time. International Finance, 4(2), 221-255.

Dow, J. \& Rahi, R. (2000). Should Speculators Be Taxed? The Journal of Business, 73(1), 89-107.

Dow, J. \& Gorton, G. (2006). Noise Traders. NBER Working Paper No 12256. National Bureau of Economic Research.

Dupont, D. Y. \& Lee, G. S. (2007). Effects of Securities Transaction Taxes on Depth and Bid-Ask Spread. Economic Theory, 31(2), 393-400.

Ehrenstein, G., Westerhoff, F. \& Stauffer, D. (2005). Tobin Tax and Market Depth. Quantitative Finance, 5(2), 213-218.

Erturk, K. A. (2006). On the Tobin Tax. Review of Political Economy, 18(1), 71-78.

European Central Bank (2004). Opinion of the ECB of 4 November 2004 at the request of the Belgian Ministry of Finance on a draft law introducing a tax on exchange operations involving foreign exchange, banknotes and currency. CON 34.

European Commission (2011a). Impact assessment accompanying the document Proposal for a Council Directive on a common system of financial transaction tax and amending Directive 2008/7/EC. SEC(2011) 1103 final.

European Commission (2011b). Proposal for a Council Directive on a common system of financial transaction tax and amending Directive 2008/7/EC. COM(2011) 594 final.

European Commission (2013a). Proposal for a Council Directive implementing enhanced cooperation in the area of financial transaction tax. $\operatorname{COM}(2013) 71$ final.

European Commission (2013b). Commission Staff Working Document Impact Assessment accompanying the document Proposal for a Council Directive implementing 
enhanced cooperation in the area of financial transaction tax. Analysis of policy options and impacts. SWD(2013) 28 final.

Farmer, J. D., Patelli, P. \& Zovko, I. I. (2005). The Predictive Power of Zero Intelligence in Financial Markets. Proceedings of the National Academy of Sciences, 102(6), 2254-2259.

Foucault, T., Sraer, D. \& Thesmar, D. J. (2011). Individual Investors and Volatility. Journal of Finance, 66(4), 1369-1406.

Friedman, M. (1953). The case for flexible exchange rates and monetary rules. In M. Friedman, (ed.), Essays in Positive Economics. University of Chicago Press.

Frino, A. \& West, A. (2003). The Impact of transaction costs on price discovery: Evidence from cross-listed stock index futures contracts. Pacific Basin Finance Journal, 11(2), 139-151.

Gomber, P., Haferkorn, M. \& Zimmermann, K. (2016). Securities Transaction Tax and Market Quality - the Case of France. European Financial Management, 22(2), 313-337.

Grahl, J. \& Lysandrou, P. (2003). Sand in the wheels or spanner in the works? The Tobin tax and global finance. Cambridge Journal of Economics, 27(4), 597-621.

Green, C. J., Maggioni, P. \& Murinde, V. (2000). Regulatory lessons for emerging stock markets from a century of evidence on transactions costs and share price volatility in the London Stock. Journal of Banking and Finance, 24(4), 577-601.

Haberer, M. (2004). Might a Securities Transaction Tax Mitigate Excess Volatility? Some Evidence from the Literature. Center of Finance and Econometrics Discussion Paper No 04/06. University of Konstanz.

Habermeier, K. \& Kirilenko, A. A. (2003). Securities transaction taxes and financial markets. IMF Staff Papers, 50(1), 165-180.

Haferkorn, M. \& Zimmermann, Z. (2013). Securities transaction tax and market quality-the case of France. https:// ssrn.com/abstract $=2229221$

Hakkio, C. S. (1994). Should we throw sand in the gears of financial markets? Federal Reserve Bank of Kansas City Economic Review, 79(Q2), 17-30.

Haldane, A. (2010). The \$100 Billion Question. BIS Review, 40.

Hanke, M., Huber, J., Kirchler, M. \& Sutter, M. (2010). The Economic Consequences of a Tobin Tax: An Experimental Analysis. Journal of Economic Behavior and Organization, 74(1-2), 58-71.

Haq, M., Kaul, I. \& Grunberg, I. (1996). The Tobin Tax: Coping with Financial Volatility. Oxford University Press.

Hau, H. (2001). Estimating the Volatility Effect of a Tobin Tax. Mimeo.

$\mathrm{Hau}, \mathrm{H}$. (2006). The role of transaction costs for financial volatility: Evidence from the Paris Bourse. Journal of the European Economic Association, 4(4), 862-890.

Hommes, C. H. (2006). Heterogeneous agent models in economics and finance. Handbook of Computational Economics, 2, 1109-1186.
Honohan, P. \& Yoder, S. (2011). Financial Transactions Tax: Panacea, threat, or damp squib? World Bank Research Observer, 26(1), 138-161.

Hu, S. Y. (1998). The Effects of the Stock Transaction Tax on the Stock Market: Experiences from Asian Markets. Pacific-Basin Finance Journal, 6(3-4), 347-364.

Huang, R. D., Cai, J. \& Wang, X. (2002). Information-Based Trading in the Treasury Note Interdealer Broker Market. Journal of Financial Intermediation, 11(3), 269-296.

Hvozdyk, L. \& Rustanov, S. (2016). The effect of financial transaction tax on market liquidity and volatility: An Italian perspective. International Review of Financial Analysis, 45, 62-78.

Imbens, G. W. \& Wooldridge, J. M. (2009). Recent developments in the econometrics of program evaluation. Journal of Economic Literature, 47(1), 5-86.

International Monetary Fund (2010). A fair and substantial contribution by the financial sector. Final Report to the G-20.

Jetin, B. \& Denys, L. (2005). Ready for implementation- Technical and legal aspects of a currency transaction tax and its implementation in the EU. World Economy, Ecology and Development (WEED).

Kaiser, J., Chmura, T. \& Pitz, T. (2007). The Tobin Tax: A Game-Theoretical and an Experimental Approach. Faculty of Economics and Statistics, Working Paper No 07/18. University of Innsbruck.

Keen, M. (2011). Rethinking the taxation of the financial sector. CESifo Economic Studies, 57(1), 1-24.

Keynes, J. M. (1936). General Theory of Employment, Interest Rates and Money. Harcourt Brace \& World.

Kiefer, D. W. (1990). The Security Transactions Tax: An Overview of the Issues. Tax Notes: 885-901.

Kupiec, P. H. (1996). Noise traders, excess volatility, and a Securities Transaction Tax. Journal of Financial Services Research, 10(2), 115-129.

Landau Report (2004). Report on innovative development funding solutions. Commissioned by President Jacques Chirac. Paris.

Lanne, M. \& Vesala, T. (2010). The effect of a transaction tax on exchange rate volatility. International Journal of Finance \& Economics, 15(2), 123-133.

Lendvai, J., Raciborski, R. \& Vogel, L. (2012). Securities transaction taxes: Macroeconomic implications in a general-equilibrium model. European Economy Economic Papers, 450.

Li, G. (2009). Transaction Costs and Consumption. Journal of Economic Dynamics and Control, 33(6), 1263-1277.

Liu, S. (2007). Securities Transaction Tax and market efficiency: Evidence from the Japanese experience. Journal of Financial Services Research, 32(3), 161-176.

Liu, S. \& Zhu, Z. (2009). Transaction Costs and Price Volatility: New Evidence from the Tokyo Stock Exchange. Journal of Financial Services Research, 36(1), 65-83. 
Mannaro, K., Marchesi, M. \& Setzu, A. (2008). Using an Artificial Financial Market for Assessing the Impact of Tobin-Like Transaction Taxes. Journal of Economic Behavior \& Organization, 67(2), 445-462.

Matheson, T. (2011). Taxing financial transactions: Issues and evidence. IMF Working Paper No 11/54.

McCrae, J. (2002). The Impact of Stamp Duty on the cost of capital. Institute for Fiscal Studies.

McCulloch, N. (2010). Tackling Instability in Markets with a Panic Tax. Institute of Development Studies, 42(5).

McCulloch, N. \& Pacillo, G. (2011). The Tobin tax: a review of the evidence. IDS Research Reports, (68), 1-77.

Meyer, S., Wagener, M. \& Weinhardt, C. (2015). Politically Motivated Taxes in Financial Markets: The Case of the French Financial Transaction Tax. Journal of Financial Services Research, 47(2), 177-202.

Nissanke, M. (2004). Revenue potential of the Tobin tax for development. In A. B. Atkinson (ed.), New Sources of Development Finance. Oxford University Press.

Oxera Consulting (2012). Taxing financial transactions: who pays the bill? $1-4$.

Oxera Consulting (2014a). What could be the economic impact of the proposed financial transaction tax? A comprehensive assessment of the potential macroeconomic impact, 1-93.

Oxera Consulting (2014b). A taxing question: the proposed financial transaction tax and public finances.

Palley, T. I. (2003). The Economic Case for the Tobin Tax. In Debating the Tobin Tax, New Rules for Global Finance.

Pellizzari, P. \& Westerhoff, F. (2009). Some effects of transaction taxes under different microstructures. Journal of Economic Behavior and Organization, 72(3), 850-863.

Philippon, T. \& Reshef, A. (2012). Wages and Human Capital in the U.S. Finance Industry: 1909-2006. The Quarterly Journal of Economics, 127(4), 1551-1609.

Phylaktis, K. \& Aristidou, A. (2007). Security Transaction Taxes and Financial Volatility: Athens Stock Exchange. Applied Financial Economics, 17(18), 1455-1467.

Pollin, R., Baker, D. \& Schaberg, M. (2003). Securities Transaction Taxes for U.S. Financial Markets. Eastern Economic Journal, 29(4), 527-558.

Poterba, J. M. \& Summers, L. H. (1995). A CEO Survey of U.S. Companies' Time Horizons and Hurdle Rates. MIT Sloan Management Review, 37(1), 43-58.

Reinhart, V. (1991). The "Tobin Tax», asset accumulation, and the real exchange rate. Journal of International Money and Finance, 10(3), 420-431.

Reisen, H. (2002, March 29). Tobin tax: Could it work? Development Center, OECD Observer.

Sachs, J. (2010, March 18). Robin Hood tax's time has come. Guardian.co.uk.
Sampson, R. C. \& Shi, Y. (2019). Are US Firms Becoming More Short-Term Oriented? Evidence of Shifting Firm Time Horizons from Implied Discount Rates, 19802013. Disponible en SSRN: https://ssrn.com/abstract $=2837524$

Sanders, D. R., Irwin, S. H. \& Leuthold, R. M. (2000). Noise trader sentiment in futures markets. In B. A. Goss (ed.), Models of Futures Markets (pp. 86-116). Routledge.

Sanders, D. R., Irwin, S. H. \& Leuthold, R. M. (2003). The Theory of Contrary Opinion: A Test Using Sentiment Indices in Futures Markets. Journal of Agribusiness, 21(1), 39-64.

Saporta, V. \& Kan, K. (1997). The Effects of Stamp Duty on the Level and Volatility of Equity Prices. Bank of England Working Papers No 71. Bank of England.

Sarwar, G. (2003). The interrelation of price volatility and trading volume of currency options. Journal of Futures Markets, 23(7), 681-700.

Schäfer, D., Schulmeister, S., Vella, J., Masciandaro, D., Passarelli, F. \& Buckley, R. P. (2012). The financial transaction tax - Boon or bane? Intereconomics, 47(2), 76-103.

Schmidt, R. (2007). The Currency Transaction Tax: Rate and revenue estimates. North-South Institute.

Schulmeister, S. (2009a). A General Financial Transaction Tax: A short cut of the pros, the cons and a proposal. WIFO Working Papers No 344.

Schulmeister, S. (2009b). Trading Practices and Price Dynamics in Commodity Markets and the Stabilizing Effects of a Transaction Tax. In Study of the Austrian Institute of Economic Research (WIFO) commissioned by the Ministry of Finance and the Ministry of Economics and Labour.

Schulmeister, S. (2009c). Aggregate Trading Behavior of Technical Models and the Yen/Dollar Exchange Rate 19762007. Japan and the World Economy, 21(3), 270-279.

Schulmeister, S. (2009d). The Profitability of Technical Stock Trading: Has it Moved from Daily to Intraday Data? Review of Financial Economics, 18(4), 190-201.

Schulmeister, S. (2009e). Asset Price Fluctuations, Financial Crises and the Stabilizing Effects of a General Transaction Tax. WIFO Working Paper No 340.

Schulmeister, S. (2009f). Technical Trading and Trends in the Dollar/Euro Exchange Rate. Study by the Austrian Institute of Economic Research (WIFO), supported by the Anniversary Fund of the Österreichische National bank.

Schulmeister, S., Schratzenstaller, M. \& Picek, O. (2008). A General Financial Transaction Tax: Motives, Revenues, Feasibility and Effects. Oesterreichisches Institut fuer Wirtschaftsforschung Working Paper.

Schwert, G. W. \& Seguin, P. J. (1993). Securities transaction taxes: an overview of costs, benefits and unresolved questions. Financial Analysts Journal, 49(5), 27-35. 
Shi, K. \& Xu, J. (2009). Entry Cost, the Tobin Tax, and Noise Trading in the Foreign Exchange Market. Canadian Journal of Economics, 42(4), 1501-1526.

Simon, D. P. \& Wiggins III, R. A. (2001). S\&P futures returns and contrary sentiment indicators. Journal of Futures Markets, 21(5), 447-462.

Song, F. M. \& Zhang, J. (2005). Securities Transaction Tax and market volatility. Economic Journal, 115(506), 1103-1120.

Spahn, P. B. (1995). International Financial Flows and Transactions Taxes: Survey and Options. IMF Working Paper No 95/60.

Šramko, F. (2015). The impact of securities transaction tax on market quality: evidence from France and Italy. International Journal of Economic Sciences, 4(3), 52-93.

Stiglitz, J. E. (1989). Using tax policy to curb speculative shortterm trading. Journal of Financial Services Research, 3(2-3), 101-115.

Su, Y. \& Zheng, L. (2011). The Impact of the Securities Transaction Taxes on the Chinese Stock Market. Emerging Market Finance and Trade, 47(1), 32-46.

Subrahmanyam, A. (1998). Transaction Taxes and Financial Market Equilibrium. Journal of Business, 71(1), 81-118.

Summers, L. H. \& Summers, V. P. (1989). When financial markets work too well: A cautious case for a Securities Transaction Tax. Journal of Financial Services Research, 3(2-3), 261-286.

Swan, P. L. \& Westerholm, J. (2001). The impact of transaction costs on turnover and asset prices: The case of Sweden's and Finland's Security Transaction Tax reductions. Mimeo.

Tobin, J. (1974). The new economics one decade older. In The Eliot Janeway Lectures on Historical Economics in Honour of Joseph Schumpeter, 1972. Princeton University Press.

Tobin, J. (1978). A proposal for International Monetary Reform. The Eastern Economic Journal, 4(3-4), 153-159.

Umlauf, S. R. (1993). Transaction taxes and the behavior of the Swedish stock market. Journal of Financial Economics, 33(2), 227-240.

Vella, J. (2012). The Financial Transaction Tax debate: Some questionable claims. In Forum on The Financial Transaction Tax - Boon or Bane? Intereconomics, 47(2), 76-103. ZBW Leibniz Information Centre for Economics.

Vella, J., Fuest, C. \& Schmidt-Eisenlohr, T. (2011). The EU Commission's proposal for a Financial Transaction Tax. British Tax Review, (6), 607-621.

Wang, C. (2001). Investor sentiment and return predictability in agricultural futures markets. Journal of Futures Markets, 21(10), 929-952.

Wang, G. H. \& Yau, J. (2000). Trading volume, bid-ask spread, and price volatility in futures markets. Journal of Futures Markets, 20(10), 943-970.

Wooldridge, J. (2007). What's new in econometrics? Lecture 10 difference-in-differences estimation. National Bureau of Economic Research, Summer Institute.

$\mathrm{Xu}, \mathrm{J}$. (2010). Noise traders, exchange rate disconnect puzzle, and the Tobin tax. Journal of International Money and Finance, 29(2), 336-357.

Zhang, L. (2001). The Impact of Transaction Tax on Stock Markets: Evidence from an emerging market. M.S. Research Paper Department of Economics East Carolina University. 


\section{En el próximo número de}

Información Comercial Española. Revista de Economía

\section{Política macroprudencial en España: instituciones e instrumentos}

La política macroprudencial en Espańa y en el marco internacional

Nuevas herramientas macroprudenciales en Espańa

Política macroprudencial y sector bancario

La extensión de las herramientas macroprudenciales a la intermediación no bancaria

Riesgos macroprudenciales en el sector asegurador

Las interconexiones en el sistema financiero

Evidencia sobre el impacto y la efectividad de las herramientas macroprudenciales

La interacción entre la política macroprudencial y la política monetaria

La interacción entre la política macroprudencial y la política fiscal

Coordinadores: Judith Arnal y Ángel Estrada
Últimos números publicados:

Tendencias actuales del análisis económico del Derecho

\section{La Unión Europea} tras la pandemia

Números en preparación:

La industria del futuro 